\title{
Teaching Histories Critically: Developing Pedagogies for Historical Literacy Across the Disciplines
}

\author{
N. R. November \\ The University of Auckland
}

\begin{abstract}
How can we leverage students' historical curiosity in order to develop deeper and more analytical engagement with the past? This essay identifies a problem in history education, a gap in our knowledge of history pedagogy. It then proposes a solution by showing why and how history educators can pursue a cross-disciplinary critique of their own pedagogies, with a view to transforming history education and expanding historical literacy. Where previous writers have focused on practices, and pre-tertiary history education, the present essay is centred on developing a methodology that will go deeper, enabling history educators to examine the pedagogical principles that underpin what happens in the tertiary-level classroom. In the research paradigm proposed here, knowledge and perceptions from teachers and students across historical disciplines are synthesised. This gives the pedagogical designs that result from engaging in collaborative 'crossover teaching' an unusually broad inter-disciplinary reach and utility. The innovative teaching designs that educators create when following this research paradigm incorporate best practices in teaching histories, and promote a newly revised 'index of historical literacy'.
\end{abstract}

Keywords: crossover pedagogies; history; historical literacy; inter-disciplinary research; pedagogy

\section{Introduction: a call for research into history pedagogies}

History is everywhere in our modern lives: on television, at the movies, on the bestseller lists. There is a thirst for knowledge of the past and a desire to use the past to situate ourselves in the present. New research into tertiary-level pedagogies of history is timely, also essential. This essay is a call to historians across the tertiary disciplines to leverage students' historical curiosity - and their responses to tertiary level learning experiences - in order to develop deeper and more analytical engagement with the past. I first identify problems and perspectives in teaching the past, then outline a five-step research process that seeks to expand the historical-critical horizons and skills of students and scholars alike.

\section{Historical literacy: problems and perspectives}

Many tertiary-level disciplines engage with historical subject matter. The ability to ask pertinent and probing questions about the past underpins many attributes of graduate study attributes in the humanities, arts, commerce, law and sciences. Asking such questions leads not only to new insights about the past and present, but also helps students to acquire transferable skills such as critical thinking, the use of evidence to support arguments, the interpretation of textual and visual sources, reflective practice and empathy. As Nokes (2011) observes, the objective of developing this kind of 'historical literacy' is to produce students 'who are able to negotiate and create the complex texts of the Information Age'.

But what exactly is 'historical literacy', and how can we best teach it? Responses to these questions are, to date, unclear. Indeed, the teaching of history has become the site for a central debate in both public and professional circles (Roberts, 2011). Several studies, including recent research, suggest that educators are not fully mining the potential of historical enquiry for developing students as 'critical beings' - individuals who, in Barnett's words, 'exert some unity of critical power over their experiences in relation to knowledge, themselves and the world' (2011, p. 109). For instance, 200- 
level Music students surveyed at the University of Auckland in 2012 tended to view music history as established fact and to have great difficulty formulating and answering complex, critically-oriented questions, as well as constructing critical, evidence-based arguments. These students' lack of skills highlights a gap in pedagogic understanding. Which other factors contribute to, or inhibit, their learning of historical literacies? What specific problems do students with various backgrounds and learning styles encounter in other historical disciplines? Which teaching strategies have tertiary educators employed to solve these problems and to what effect? These questions demand the attention of tertiary-level history teachers across the disciplines.

Historical literacy is already of critical interest in history studies (Duvenage, 1993; Monte-Sano, 2001; Nokes, 2013; Nokes, 2010; Reddy \& Van Sledright, 2010; Wineberg, 2001). Historians and history educators have given much attention to historical literacy, and how best to promote it in teaching and research. There has also been some research into developing historical literacy within various disciplines (Shanahan \& Shanahan, 2008; Damico and M. Baildon, 2011; Broomhead, 2005). A large body of literature is devoted to 'content area literacy', that is, the effective teaching of literacy skills, broadly conceived, within various subject areas. For instance, a recent New Zealand research project explores the role of the National Certificate of Education Achievement in motivating students to develop disciplinary expertise (M. Sheehan, K. Hunter, \& J. Howson, 2013). This study, and much of the related literature, deals with pre-university education, although it is at the tertiary level that learners usually first encounter sharply divided 'communities of practice' in the various academic disciplines (Shanahan \& Shanahan, 2008). A new standard of literacy is demanded at university, and students struggle with the tasks of asking and interpreting questions posed —and historical questions are often by nature complex.

To date there is no consensus on the definition of historical literacy. In a stock-take of teaching historical literacy, Taylor and Young (2003) define the term as 'a systematic process with particular sets of skills, attitudes and conceptual understandings that mediate and develop historical consciousness'. They develop an index of historical literacy comprising thirteen categories, which are a mixture of 'skills, attitudes and conceptual understandings'. These categories include, for example, 'narratives of the past', 'representational expression', and 'ICT [Information and Communication Technology] understandings'. This index is a start towards a definition of historical literacy, but it is also loose and mixed in terms of its categories. In 2009, Lee signalled the need for further work in this area: 'we need a workable notion of historical literacy'. Such a notion is, however, still not available.

\section{The fundamental question: how are we teaching history?}

There is a need for a definition of historical literacy that is both comprehensive and coherent. |One can start with the usefully broad and yet practical and cohesive idea of historical literacy as a set of practices that can be brought into classroom teaching and learning practice. New practice-centred teaching models in history have already been developed, which one can critique and adapt. For example, Indiana University’s History Learning Project identifies the six 'operations' involved in what they term 'historical thinking' (http://www.iub.edu/ hlp/beta/hlp.html). These operations are broader, more inclusive, and at the same time more unified than those offered by Taylor and Young. They are 'understanding the nature of the historical discipline and analysis', dealing with primary and secondary sources, 'constructing and evaluating arguments', and historical research and writing. These operations can help in compiling the components 
of the practice of historical literacy; however, they do not recognise the diversity of approaches of teachers in historical disciplines other than history itself. More research is needed into how historical literacy can best be promoted across the historical disciplines. Which concepts of historical literacy can be effectively shared and transferred within the disciplines, and why?

Ways of obtaining answers to these questions are outlined below. More fundamentally, though, we need explore not just what we are teaching when we teach historical literacy or historical thinking, but also how. History pedagogy is woefully under-researched. In an important investigation into teaching history, for example, Lévesque (2008) explores interdisciplinary approaches to history, but remains moored to 'historical thinking' (considering what we are teaching), rather than investigating the range of relevant pedagogies that would be appropriate to those disciplines (considering how we might best teach). Roberts (2011) recognises this gap and calls for a 'pedagogy of historical literacy and thinking'. His call has yet to be fully heeded: new research still tends to focus on the 'what' of historical studies teaching; hence the generation of lists or indexes of 'historical literacy' and 'historical understanding'. As Roberts notes, each list or index assumes or implies a particular pedagogy, but the question of why certain skills, concepts or attitudes germane to the historian are taught in that way, in comparison to other ways, remains largely unexamined. This is the case, for example, in Shep's (2014) project 'Moving beyond the Threshold: Investigating Digital Literacies and Historical Thinking in New Zealand Universities'. Shep's research team explored the extent to which 'digital media and methodologies' (related to Taylor and Young's 'ICT understandings') play a role in learning that involves the acquisition and retention of disciplinary 'threshold concepts' (core concepts that transform one's perception of a given subject, once understood). Which other concept types do educators and students consider useful in learning history, and (equally importantly) which are the most effective ways of teaching those concepts?

\section{Methods: 'Crossover Pedagogies'}

We need to first capture how historical literacy is taught across disciplines and then use that to establish a dialogue between history educators about the most useful and transferable pedagogies across the historical disciplines. Roberts' first step in building a pedagogy of history is to collaborate with museum educators in order to develop a more encompassing definition of historical literacy. This is a helpful start, but museum studies is just one of several historical disciplines that can inform the pedagogies that develop historical literacy. Research is needed into how historical literacy can best be promoted in diverse learners studying diverse histories.

To move forward with this research, and specifically to enable pedagogical exchange between history educators across disciplines, one can utilise Nash's (2009) concept of a 'crossover pedagogy'. Nash brings a co-teacher from another area of the university (student affairs) into his philosophy classroom to help open up dialogues with his students on moral and philosophical questions. His approach allows for multiple viewpoints, and a broad, critical understanding of meaning and knowledge; but he provides no theory as to what a 'crossover pedagogy entails', nor how one might assess and promote the most useful pedagogies across the disciplines.

One can both clarify and broaden Nash's work with a new concept of 'crossover pedagogies'; that is, approaches to teaching that are drawn from, or applied in, 
disciplines other than one's own. An ideal methodology for exploring 'crossover pedagogies' is one that is broadly based on action research and informed by educational design research (also termed 'design-based research') with two (or more) cycles of action and reflection (described in Phases 3 and 4, below; see especially Reeves, Herrington, \& Oliver, 2005; and Reeves, McKenney, \& Oliver, 2010). Educational design research typically proceeds from a complex, general question to specific course designs that are to be implemented in cycles. In educational design research, investigators seek out and apply guidelines or 'design principles' developed by other educators working in similar contexts. They then refine these educational designs iteratively, based on feedback from students and peers. These cycles can be carried out by what I will term 'crossover teaching partnerships', where each member of the partnership is from a different historical discipline.

One can usefully focus attention on upper-level (primarily 200-level) students because tertiary students are to some extent socialised within their chosen discipline by their second year. They are starting to understand what it means to study that discipline and to have a sense of their own approaches to and preferences for learning in the discipline. One can then draw on these students' discipline-based understandings and learning preferences as part of the research.

Five phases for the research are outlined below, with aims and methodological suggestions for each step. Phase 1 entails data gathering. Phase 2 then involves analysis and theorising about best practices in the teaching of historical literacy. Phases 3 and 4 comprise cycles of action and reflection: implementation of crossover teaching interventions, and analysis of feedback on these, respectively. Procedures for obtaining further feedback on the entire process are then detailed in Phase 5.

\section{Phase 1: exploring history pedagogies}

Aim The primary aim of Phase 1 is to gather data on history pedagogies that are applied across the historical disciplines, together with understandings of historical literacy. This will enable a broadening and re-formulation of previous scholars' indexes and categories of 'historical literacy' and 'historical understanding' in Phase 2. Researchers will then be in a position to examine their teaching, describing and evaluating the various pedagogies that they implicitly or explicitly deploy.

Methods In this phase, teachers from different historical disciplines pair up and have an initial discussion about their understandings of historical literacy and their approaches to teaching it. Discussion questions should be designed to encourage the sharing of information about pedagogical approaches, and their efficacy in the selected disciplines. One can be guided in here by the HEART strategy (HEaring And Realising Teaching-voice) developed by Blake and Donald (2009). This strategy uses visualisation techniques and concept mapping in order to build up a picture of the pedagogical beliefs that underpin a given teacher's practices. Concept mapping will also help the crossover teaching partners to establish a working list of the practices that they consider central to teaching historical literacy.

\section{Phase 2: reformulating the index of historical literacy}

Aims To analyse and reflect on the pedagogical approaches and definitions that one uncovers in Phase 1, then use the knowledge gained in reformulating the 'index of historical literacy', drawing on best practices from across the historical disciplines.

Methods Ultimately, the HEART strategy is designed to assist with the sharing of teaching designs and resources, but Blake and Donald (2009) recognise the need to first 
make explicit underlying teaching beliefs of the participants. In analysing results, one can to try to understand why a given history teacher, working within a given discipline, chooses certain content and 'delivers' that content in certain ways. The visual output of the HEART strategy facilitates comparisons of teachers' approaches from across the disciplines.

Shulman (2005) develops a typology of 'signature pedagogies in the professions', types of teaching that organise the fundamental ways in which future practitioners are educated for their new professions. As well as using the visual output of the HEART strategy, one can compare the data gathered in Phase 1 to the 'signature pedagogies' outlined by Shulman, to see if the typologies that he outlines are present and whether they are helpful for categorising the new data. Here, 'future practitioners' are 200-level university students, and the 'professions' are the historical disciplines.

Researchers can also compare the concept maps produced by staff participants to the published lists of 'historical literacy' and 'historical understanding' by key spokespeople and institutions, such as Taylor and Young, and Indiana University History Department. Questions to ask include: to what extent are their models duplicated here? Are there new categories? Crucially: how do teachers' practices vary across the disciplines?

Regarding instructors' evaluative comments on their teaching, the well-established Learning Paradigm developed by Barr and Tagg (1995) can provide guidance as to what constitutes 'best practice'. Under this paradigm, knowledge is understood as shaped by individual experience; learning is considered as student centred; and ideal learning environments are considered to be those that are cooperative, collaborative, and supportive. This model of learning as it fits in with social constructivists' views of fostering 'communities of practice' and 'student-centred learning' (Wenger, 1998; Wenger, McDermott, and Snyder, 2002).

\section{Phase 3: Crossover Teaching Part I}

Aim The overall aim of this phase is to implement and then evaluate new teaching interventions, based on the critical evaluation of the history pedagogies that one has surveyed and reflected on in Phases 1 and 2.

Method Using the pairs of teachers from Phase 1, a pedagogical strategy for teaching history that has proven useful (to teachers and students alike) in one's own discipline can be applied in that of one's partner. For example, a teacher in History might deploy an effective teaching practice from History Studies in a Music History course, and vice versa. One can exchange not only 'signature pedagogies' but also the respective subjects' key historical practices. Thus, for example, music students might consider how an 'event'- or conflict-centred view of history (rather than a composeror musical score-centred view) helps them to think about the concept of periodization.

In Phases 3 and 4, the teaching partners should meet as soon as possible after each teaching intervention, to reflect on what worked and what did not in the respective classes, and why. Critical Incident Questionnaires (CIQs), as developed by Brookfield (2006), can form a key source of information on student perceptions following from each of the teaching interventions. These questionnaires provide 'awareness of how students are experiencing their learning and perceiving [the teacher's] actions' (p. 27).

\section{Phase 4: Crossover Teaching Part II}


Aim The overall aim of this phase is to further develop the Crossover Teaching begun in Phase 2. Here one can move from the teaching of a known concept with a known pedagogical style in another discipline, to the application of a new pedagogy from another discipline in one's own course.

Methods A pedagogical strategy for teaching history that has proven useful by one's crossover teaching partner can now be tried out in one's own class. For example, a teacher in English Literature might deploy a new teaching strategy, adapted from that of a colleague in Art History, to illustrate a key concept within his/her own course, and vice versa.

\section{Phase 5: obtaining and analysing feedback on the interventions}

Aim Ultimately, one needs to discover the extent to which the various history pedagogies are transferable and useful in new disciplinary contexts, from both the staff and student perspective, and to assess the degree to which student learning of key practices, operations and understandings in historical studies were improved.

Methods After Phase 4, surveys of those history educators who have carried out interventions can be carried out, with questions targeted to the crossover teaching partners' assessment of both the 'what' (content) and the 'how' (pedagogical basis) of the interventions deployed. One can then compare the results of these surveys to the data obtained from pair discussions carried our in Phase 1, mapping and documenting any shifts in understanding that might relate to a given educator's discipline.

A further evaluation tool that is useful in this context is 'ipsative' assessment. As discussed by Hughes (2009), this tool is ideal for the 'before and after' study of student outcomes that is deployed in this research. Here, the 'ipsative' assessment could, for example, be a form of formative student self-assessment, entailing two linked assignments, one at the beginning of the course and one at the end. The first assignment can provide a picture, albeit a partial one, of what students know about history in relation to the given discipline at the start of the course, allowing the instructor to identify and use this prior state of understanding as the basis for development. The second assignment can be designed to provide information about what knowledge students gain from the 'cross taught' units and new pedagogies.

\section{Conclusion: potentials of the process}

The research outlined here is firmly focused on enhancing learner outcomes: it aims to lead to significant improvements in terms of historical skills and understandings across various disciplines for diverse learners, including men and women, mature students, and international students from various cultures. These learner outcomes are expected to include new insights about the past and present, and also the acquisition of transferable skills such as critical thinking, use of evidence to support arguments, selfreflection, empathy and interpretative facility with many textual and visual sources.

In carrying out 'crossover pedagogies', teachers are simultaneously cast as educational researchers, and their perceptions and actions inform all stages of the research process, as do those of their students. Thus the investigators stand to gain many insights from each other, and from their students. The interventions that the teaching partners develop and implement can be expected to significantly strengthen their abilities to teach historical literacies, and to broaden pedagogical practices so as to engage a wider variety of learners more deeply in history studies than previously. Further, insofar as 
researchers seek through this process to encompass 'other histories' and other ways of studying/narrating history than the mainstream ones, it will help to promote equity in tertiary education.

The project's research processes are designed to enable educators' active learning from one another in two cycles, which proceed from 'known' pedagogies (one's own), to relatively unknown ones (those of one's partner). Of course, these cycles of planning, action, and reflection can be extended, so that educators involved in the project can be engaged in reflective and developmental teaching activities with other partners, and pedagogical practices drawn from other disciplines, or those that are based on other practices in the revised Index of Historical Literacy.

While this project focuses on tertiary-level education, researchers can also aim to engage the attention and feedback of secondary-level teachers. This can be carried out with a view to improving the logic and scaffolding of history teaching across educational sectors. This broader purview is important: tertiary-level history study demands new levels of literacy, creating significant new demands on learners; but these learners come to tertiary study with views of history and approaches to learning that have already been decisively shaped through their secondary-level studies.

\section{References}

Barnett, R. (1997). Higher Education: A Critical Business. Buckingham, UK: SRHE and Open University Press.

Barr, R. \& Tagg, J. (1995). From Teaching to Learning: A New Paradigm for Undergraduate Education, Change, 27(6), 12-25.

Blake, A. \& C. Donald, C. (2009). Reviewing Learning Designs with HEART: A Learning Design Support Strategy. Paper presented at ASCILITE 2009, Auckland:

http://www.academia.edu/5632327/Reviewing_learning_designs_with_HEAR T_A_learning_design_support_strategy.

Broomhead, P. (2005). (Re)Imagining Literacies for the Music Classroom. In R. J. Draper (Ed.), (Re)Imagining Content-Area Literacy Instruction (pp. 69-81). New York: Teacher's College Press.

Brookfield, S. (2006). The Skillful Teacher: On Technique, Trust, and Responsiveness in the Classroom, 2ed. San Francisco: Jossey Bass.

Damico, J. S. \& Baildon, M. (2011). Content Literacy for the $21^{\text {st }}$ Century:

Excavation, Elevation and Relational Cosmopolitanism in the Classroom, Journal of Adolescent \& Adult Literacy, 55(3), 232-43.

Duvenage P. (ed.). (1993). Studies in Metahistory. Pretoria: Human Sciences

Research Council.

Hughes, G. (2011). Towards a Personal Best: A Case for Introducing Ipsative

Assessment in Higher Education, Studies in Higher Education, 36(3), 353-367.

Lee, P. (2009). Historical Literacy: Theory and Research, International Journal of Historical Learning, Teaching and Research, 9: http://www.heirnet.org/IJHLTR/journalstart.htm.

Lévesque, S. (2008). Thinking Historically. Toronto: University of Toronto Press. Nash, R. J. (2008). Crossover Pedagogy: The Collaborative Search for Meaning, About Campus, 14, 2-9.

Nokes, J. (2013). Building Students' Historical Literacies: Learning to Read and Reason with Historical Texts and Evidence. New York: Routledge. 
Nokes, J. (2011). Historical Literacy, Social Studies: Newsletter of the Utah State Office of Education, 6-9.

Nokes, J. (2010). Reimagining Literacy for History Classrooms. In A. P. Jensen, J. D., Nokes, \& D. Siebert (Eds.), (Re)imagining Literacies for Content-Area Classrooms (pp. 159-171). New York: Teachers College Press.

Reddy K., \& Van Sledright, B. (2010). 'Epistemic Change in History Education' Paper presented at the annual conference of the College and University

Faculty Assembly, Denver Colorado.

Reeves, T., Herrington, J. \& Oliver, R. (2005). 'Design Research: A Socially Responsible Approach to Instructional Technology in Higher Education', Journal of Computing in Higher Education, 16(2), 97-119.

Reeves, T., McKenney, S. \& Oliver, R. (2010). 'Publishing and Perishing: The Critical Importance of Educational Design Research’. Paper presented at ASCILITE 2010, Sydney.

Roberts, P. (2011). 'From Historical Literacy to a Pedagogy of History'. Paper presented at Building Bridges for Historical Learning: Connecting Teacher Education and Museum Education, Canberra:

http://learnonline.canberra.edu.au/file.php/5882/Discussion_Paper_From_hist orical_iteracy_to_a_pedagogy_of_history.pdf.

Shulman, S. (2005). 'Signature Pedagogies in the Professions’, Daedalus, 134(3),

59.

Shanahan, T. \& Shanahan, C. (2008). 'Teaching Disciplinary Literacy to Adolescents: Rethinking Content-Area Literacy', Harvard Educational Review, 78(1), 40-59.

Sheehan, M., K. Hunter, \& Howson, J. (2013). “"Thinking Historically”: The Role of

NCEA Research Projects in Motivating History Students to Develop Disciplinary Expertise'. Website: http://www.tlri.org.nz/tlri-research/researchcompleted/school-sector/\%E2\%80\%98thinking-historically\%E2\%80\%99-rolencea-research-projects.

Shep, S. (2014). 'Moving Beyond the Threshold: Digital literacies and historical thinking in New Zealand Universities'. Website: http://www.ee.ucl.ac.uk/ mflanaga/abstracts/TC14Abstract30.pdf.

Taylor T. \& Young, C. (2003). Making History: A Guide for the Teaching and Learning of History in Australian Schools. Website: http://www.hyperhistory.org/index.php?option=displaypage\&Itemid=220\&op $=$ page.

Wenger, E. (1998). Communities of Practice: Learning, Meaning, and Identity. Cambridge, UK: Cambridge University Press.

Wenger, E., McDermott, R., and W. C. Snyder, W. (2002). Cultivating Communities of Practice: A Guide to Managing Knowledge. Boston: Harvard Business School Press.

Wineberg, S. (2001). Historical Thinking and Other Unnatural Acts. Philadelphia: Temple University Press. 